\title{
Extreme variations in racial rates of total hip arthroplasty for primary coxarthrosis: a population-based study in San Francisco
}

\author{
Franklin T Hoaglund, Calvin S Oishi, Gus G Gialamas
}

\begin{abstract}
Objectives-To compare the incidence of all total hip arthroplasty, and total hip arthroplasty for primary coxarthrosis, among the Asian, black, Hispanic, and white populations living in one locale.

Methods-We identified all San Francisco residents who underwent total hip replacements (THR) in the 17 hospitals for adults within or near San Francisco County during a five year period. Preoperative pelvic radiographs were read without prior knowledge of the gender or race of the subject, to diagnose the specific hip diseases. Age standardised THR incidence by race and gender was determined, as was the comparative THR incidence for specific diagnosis (primary and secondary osteoarthritis).
\end{abstract}

Results-The greatest annual rate of total hip replacement occurred in white women (97 per 100000 population), followed by white men, black women, black men, Hispanic women, and Hispanic men. The smallest numbers were found in Asians, whose THR rate was $10 \%$ that of whites. A primary coxarthrosis diagnosis was greatest among white subjects $(66 \%)$, followed by black subjects $(54 \%)$, Hispanics (53\%), and Asians (28\%). Age standardised THR rates for primary coxarthrosis per 100000 population were likewise greatest among whites (43.0) and least among Asians (1.3 for Chinese). Mean age of patients undergoing THR for primary coxarthrosis was 70 years for white subjects and almost a decade younger in all other groups.

Department of Orthopaedic Surgery, University of California, San Francisco, USA F T Hoaglund

Department of Orthopaedic Surgery, University of Hawaii, Honolulu

C S Oishi

653 Camino de los Mares, Suite 109, San Clemente, CA 92673, USA

G G Gialamas

Correspondence to:

Franklin T Hoaglund,

Department of Orthopaedic Surgery, 500 Parnassus, Room MU-320 W, B 0728 , University of California, San Francisco CA 94143-0728, USA.

Accepted for publication 29 September 1994
Primary coxarthrosis is a common problem in America, ${ }^{1}$ Northern Europe, ${ }^{23}$ and Scandinavia $^{4-6}$ and accounts for about $67 \%$ of the total hip replacements (THR) performed in these countries. In contrast, primary coxarthrosis occurs infrequently among the Hong Kong Chinese, ${ }^{7}$ East Indians, ${ }^{8}$ Koreans, ${ }^{9}$ Japanese, ${ }^{10}$ black South Africans ${ }^{11}$ and black Jamaicans. ${ }^{12}$ An understanding of the causes of low incidence in non-white peoples could contribute to our understanding of the aetiology of this disease. However, there have been no population based studies either to document comparative prevalence or to investigate the role of genetic and cultural factors.

The city of San Francisco, the population of which is more than $50 \%$ non-white, including large numbers of black subjects, Chinese, Filipinos, and Hispanics, provides a defined geographical location where treatment for hip disease among different races can be compared. We did so by determining the number of total hip replacements for various hip diseases, including osteoarthritis, among various racial groups in San Francisco, and estimating the incidence of surgically treated hip disease in those groups. THR is virtually the only surgical procedure performed for the pain of any hip disease which has not been relieved by conservative treatment.

\section{Patients and methods}

With a computer aided search of hospital records, we identified all patients living in the San Francisco area who underwent THR operation in the 17 hospitals for adults within or near the boundaries of San Francisco County during the five year period 1984-88. Medical record number, age, gender, race, diagnostic code for the hip disease, and zip code were recorded for each patient. Using specific ethnic information included in the medical record or acquired from the orthopaedic surgeon, patients identified as Asian were categorised by specific national origin.

The preoperative pelvic radiographs of white patients discharged between 1 January 1984 and 31 December 1988, and of all Asian, black, and Hispanic patients for all five years of the study were sought for examination. Radiographs were read by one of the authors (FTH) without knowledge of the gender or race of the subject, except for Japanese and Chinese patients whose family names gave obvious clues to race. When osteoarthritis was diagnosed, the pattern of disease was characterised-as secondary when predisposing conditions such as congenital hip dysplasia or 
Table 1 Validation of radiographs in San Francisco residents undergoing total hip replacement, 1984-88, by race

\begin{tabular}{lccc}
\hline Race & \multirow{2}{*}{$\begin{array}{l}\text { No of } \\
\text { patients }\end{array}$} & \multicolumn{2}{c}{ Radiographs examined } \\
\cline { 3 - 4 } & & No & $\%$ \\
\hline Chinese & 44 & 43 & 98 \\
Japanese & 10 & 10 & 100 \\
Filipino & 16 & 16 & 100 \\
Hispanic & 62 & 47 & 76 \\
Black & 143 & 114 & 80 \\
White & $285 \dagger$ & 199 & 80 \\
Other & $16 \ddagger$ & 9 & 56
\end{tabular}

†There were 1332 white patients over the five year period; the 285 white patients operated on in 1988 were selected for validation.

$\ddagger$ One Hawaiian; four American Indian; one East Indian; one Korean; nine unknown.

Perthes disease were recognised, or as primary coxarthrosis in the remainder. ${ }^{13}$ Uncertain radiograph diagnoses of rheumatoid arthritis, ankylosing spondylitis, or sepsis were confirmed by reviewing the medical records. Cases of revision THR were recorded separately.

Using these radiographic diagnostic data, yearly age standardised rates of total hip arthroplasty for each of the subsets causing the hip disease (primary and secondary osteoarthritis) were compiled by gender and race. The population for 1986, the midpoint of the study, was used for this calculation and was based on a linear extrapolation of San Francisco census data between 1980 and the 1990. ${ }^{14}$ The following formula was used:

No of cases of primary coxarthrosis

No of pelvic radiographs examined

$$
\begin{aligned}
& \times \frac{\text { No of total hip replacements during five years }}{1986 \text {-specific racial population }} \\
& \times \frac{100000}{5}
\end{aligned}
$$

The resulting rate was adjusted for age, using the method of direct standardisation..$^{15}$ Rates of THR for all causes, including revision, were calculated by the formula:

$\frac{\text { All total hip replacements during five years }}{1986 \text {-specific racial population }} \times \frac{100000}{5}$

These rates were also standardised for age using the method of direct standardisation.

We used logistic regression to estimate the effects of both race and age on the probability of a patient having a total hip replacement for primary osteoarthritis. Both race and age categories were included in the logistic regression as dummy indicator variables. Separate analyses were carried out for females and males.

\section{Results}

In the 15 San Francisco hospitals treating adult patients and two more hospitals located near the county line, a total of 1767 total hip replacements were performed between 1984 and 1988 inclusive, for 1623 patients whose address included a San Francisco zip code. One hundred and twenty four of these patients had a second THR, with a new primary or revision, and 10 had a third operation. Complete demographic data were available for 1589 patients. We evaluated 438 preoperative pelvic radiographs (table 1) which included 344 from patients awaiting primary total hip replacement surgery. The diagnoses obtained by examining these 344 radiographs were rheumatoid arthritis, ankylosing spondylitis, avascular necrosis, neoplasia (primary or secondary), sepsis, osteomyelitis, proximal femur fracture, Perthes disease, congenital hip dislocation or dysplasia, and primary coxarthrosis. Of these diagnoses, primary coxarthrosis was found in $66 \%$ of the white patients, $55 \%$ of black subjects, $54 \%$ of Hispanics, and fewer than $30 \%$ of Asians (table 2). Avascular necrosis was diagnosed in $29 \%$ of the black patients.

White women had the greatest annual rate for total hip replacement (97 cases per 100000 population), followed by white men ( 55 per 100000 population) (table 3). Black women and men had the next highest rates, with 36 and 34 cases per 100000 population, respectively, followed by Japanese and Hispanic women (23 and 14 cases per 100000 population, respectively). Except among the black and Hispanic populations, the rates for women were much greater than those for men.

The standardised rates of THR for primary coxarthrosis followed the same racial pattern as that for all cases of total hip replacement, except that the differences between racial groups were far more pronounced. White women and men had the greatest annual rates (53 and 34 cases per 100000 population, respectively) followed by black subjects, whose incidence was about $33 \%$ that of whites $(19.2$ for women and $10 \cdot 1$ for men). Hispanic patients had the next greatest rates $(6 \cdot 2$ and $6 \cdot 3$ per 100000 ), and Asians had the lowest rate$5 \%$ that of the white population (less than $3 \cdot 1$ per 100000$)$. The difference between the sexes

Table 2 Diagnosis based on preoperative pelvic radiographs in San Francisco patients undergoing primary total hip

\begin{tabular}{|c|c|c|c|c|c|c|c|c|c|c|c|c|}
\hline \multirow[t]{2}{*}{ Diagnosis } & \multicolumn{2}{|c|}{ Chinese } & \multicolumn{2}{|c|}{ Fapanese } & \multicolumn{2}{|c|}{ Filipino } & \multicolumn{2}{|c|}{ Hispanic } & \multicolumn{2}{|c|}{ Black } & \multicolumn{2}{|c|}{ White } \\
\hline & No & $\%$ & No & $\%$ & No & $\%$ & No & $\%$ & No & $\%$ & No & $\%$ \\
\hline Avascular necrosis & 4 & 10.25 & 0 & 0 & 3 & $21 \cdot 43$ & 6 & $15 \cdot 3$ & 24 & $28 \cdot 60$ & 8 & $5 \cdot 00$ \\
\hline Fracture & 14 & $36 \cdot 80$ & 4 & 50 & 3 & $21 \cdot 43$ & 1 & $2 \cdot 6$ & 10 & 11.90 & 26 & $16 \cdot 1$ \\
\hline $\begin{array}{l}\text { Rheumatoid } \\
\text { arthritis/spondylitis }\end{array}$ & 6 & $15 \cdot 80$ & 2 & 25 & 1 & $7 \cdot 14$ & 8 & $20 \cdot 5$ & 1 & $1 \cdot 20$ & 2 & $1 \cdot 20$ \\
\hline Tumour, sepsis & 1 & $2 \cdot 60$ & 0 & 0 & 2 & $14 \cdot 30$ & 2 & $5 \cdot 10$ & 1 & $1 \cdot 20$ & 8 & $5 \cdot 00$ \\
\hline $\begin{array}{l}\text { Congenital hip } \\
\text { dysplasia/Perthes }\end{array}$ & 6 & $15 \cdot 80$ & 1 & $12 \cdot 5$ & 1 & $7 \cdot 10$ & 1 & $2 \cdot 60$ & 2 & $2 \cdot 40$ & 10 & $6 \cdot 20$ \\
\hline Primary osteoarthritis & 7 & $18 \cdot 40$ & 1 & $12 \cdot 5$ & 4 & $28 \cdot 60$ & 21 & $53 \cdot 80$ & 46 & $54 \cdot 80$ & 107 & $66 \cdot 40$ \\
\hline Total & 38 & & 8 & & 14 & & 39 & & 84 & & 161 & \\
\hline Revision total & 5 & & 2 & & 2 & & 8 & & 30 & & 38 & \\
\hline
\end{tabular}
replacement, $1984-88$, by race 
Table 3 Age standardised annual rates of total hip replacement (THR) for San Francisco (SF) residents, 1984-88, by gender and race

\begin{tabular}{lrrrrrr}
\hline & Chinese & fapanese & Filipino & Hispanic & Black & White \\
\hline Women & & & & & & \\
THR with SF zip code & 29 & 8 & 11 & 35 & 75 & 842 \\
1986 SF population & 56442 & 6852 & 21582 & 45999 & 40816 & 167709 \\
THR/100 000 population & $9 \cdot 9$ & $23 \cdot 4$ & $9 \cdot 2$ & 13.9 & 36.2 & $97 \cdot 3$ \\
Men & & & & & & \\
THR with SF zip code & 15 & 2 & 5 & 27 & 68 & 490 \\
1986 SF population & 52834 & 5194 & 19315 & 47780 & 38932 & 176662 \\
THR/100 000 population & $5 \cdot 7$ & $7 \cdot 7$ & $5 \cdot 2$ & 11.3 & 34.3 & 54.9 \\
All & & & & & & \\
THR with SF zip code & 44 & 10 & 16 & 62 & 143 & 1332 \\
1986 SF population & 109276 & 12046 & 40897 & 93779 & 79748 & 344371 \\
THR/100 000 population & 7.9 & 16.6 & 7.3 & 12.6 & 35.3 & 75.5 \\
\hline
\end{tabular}

^Estimate based on 1980 and 1990 census 9 .

Table 4 Age standardised annual rates of primary total hip replacement for different diagnoses per 100000 population, 1984-88, by gender and race

\begin{tabular}{llllllr}
\hline & Chinese & Fapanese & Filipino & Hispanic & Black & White \\
\hline Women & & & & & & \\
Avascular necrosis & $0 \cdot 7$ & 0 & $0 \cdot 9$ & $0 \cdot 9$ & $5 \cdot 7$ & $4 \cdot 6$ \\
Fracture of hip & $4 \cdot 3$ & $5 \cdot 8$ & $3 \cdot 4$ & $0 \cdot 7$ & $2 \cdot 3$ & $14 \cdot 4$ \\
Rheumatoid/Spondylitis & $0 \cdot 7$ & $5 \cdot 8$ & 0 & $3 \cdot 7$ & 0 & $1 \cdot 6$ \\
Secondary osteoarthritis & $1 \cdot 8$ & $2 \cdot 9$ & $0 \cdot 9$ & 0 & $1 \cdot 1$ & $6 \cdot 7$ \\
Primary osteoarthritis & $1 \cdot 4$ & $2 \cdot 9$ & $3 \cdot 1$ & $6 \cdot 2$ & $19 \cdot 2$ & $52 \cdot 6$ \\
Men & & & & & & \\
Avascular necrosis & $0 \cdot 8$ & 0 & $2 \cdot 1$ & $1 \cdot 6$ & $9 \cdot 3$ & $1 \cdot 5$ \\
Fracture of hip & $0 \cdot 8$ & $7 \cdot 7$ & 0 & 0 & $4 \cdot 6$ & $5 \cdot 8$ \\
Rheumatoid/Spondylitis & $1 \cdot 5$ & 0 & $1 \cdot 0$ & $0 \cdot 4$ & 0.6 & 0 \\
Secondary osteoarthritis & $0 \cdot 4$ & 0 & 0 & $0 \cdot 8$ & 0 & 1.8 \\
Primary osteoarthritis & $1 \cdot 1$ & 0 & 0 & $6 \cdot 3$ & $10 \cdot 1$ & 33.9 \\
\hline
\end{tabular}

Table 5 Estimated rate (Rate) of total hip replacement for primary coxarthrosis per 100000 population, per year, for men and women in different racial subpopulations, obtained from logistic regressions

\begin{tabular}{|c|c|c|c|c|c|}
\hline \multirow{2}{*}{$\begin{array}{c}\text { Age } \\
(y r)\end{array}$} & \multirow[t]{2}{*}{ Race } & \multicolumn{2}{|l|}{ Men } & \multicolumn{2}{|l|}{ Women } \\
\hline & & Rate & $90 \% C L$ & Rate & $90 \% C L$ \\
\hline $0-39$ & $\begin{array}{l}\text { Chinese } \\
\text { Filipino } \\
\text { Japanese } \\
\text { Hispanic } \\
\text { Black } \\
\text { White }\end{array}$ & $\begin{array}{l}0 \cdot 6 \\
0 \cdot 7 \\
1 \cdot 0 \\
2 \cdot 1 \\
3 \cdot 9 \\
5 \cdot 9\end{array}$ & $\begin{array}{l}0.2 \text { to } 2.0 \\
0.1 \text { to } 4.0 \\
0.1 \text { to } 14.0 \\
0.8 \text { to } 5 \cdot 3 \\
1.8 \text { to } 8.4 \\
3.3 \text { to } 10.8\end{array}$ & $\begin{array}{l}0 \cdot 6 \\
0 \cdot 6 \\
1 \cdot 0 \\
1 \cdot 1 \\
2 \cdot 1 \\
4 \cdot 7\end{array}$ & $\begin{array}{l}0.2 \text { to } 1.7 \\
0.2 \text { to } 2.6 \\
0.2 \text { to } 5.3 \\
0.4 \text { to } 2.8 \\
0.9 \text { to } 5.0 \\
2.3 \text { to } 9.8\end{array}$ \\
\hline $40-49$ & $\begin{array}{l}\text { Chinese } \\
\text { Filipino } \\
\text { Japanese } \\
\text { Hispanic } \\
\text { Black } \\
\text { White }\end{array}$ & $\begin{array}{r}1 \cdot 8 \\
2 \cdot 1 \\
2 \cdot 9 \\
6 \cdot 2 \\
11 \cdot 5 \\
17 \cdot 5\end{array}$ & $\begin{array}{l}0 \cdot 5 \text { to } 6 \cdot 1 \\
0 \cdot 4 \text { to } 12 \cdot 3 \\
0 \cdot 2 \text { to } 41 \cdot 7 \\
2 \cdot 3 \text { to } 16 \cdot 5 \\
5 \cdot 1 \text { to } 26 \cdot 2 \\
9 \cdot 2 \text { to } 33 \cdot 2\end{array}$ & $\begin{array}{r}3 \cdot 1 \\
3 \cdot 2 \\
5 \cdot 1 \\
5 \cdot 3 \\
10 \cdot 8 \\
23 \cdot 7\end{array}$ & $\begin{array}{l}1.2 \text { to } 8.1 \\
0.8 \text { to } 12.5 \\
1.0 \text { to } 25.9 \\
2.1 \text { to } 13.5 \\
4.9 \text { to } 23.5 \\
12.6 \text { to } 44.7\end{array}$ \\
\hline $50-59$ & $\begin{array}{l}\text { Chinese } \\
\text { Filipino } \\
\text { Japanese } \\
\text { Hispanic } \\
\text { Black } \\
\text { White }\end{array}$ & $\begin{array}{r}7 \cdot 6 \\
9 \cdot 1 \\
12 \cdot 3 \\
26 \cdot 5 \\
49 \cdot 5 \\
74 \cdot 9\end{array}$ & $\begin{array}{l}2.5 \text { to } 23.3 \\
1.7 \text { to } 49.2 \\
0.9 \text { to } 171.0 \\
11.3 \text { to } 62.0 \\
25.8 \text { to } 95.0 \\
48.8 \text { to } 115.0\end{array}$ & $\begin{array}{l}12 \cdot 2 \\
12 \cdot 3 \\
19 \cdot 8 \\
20 \cdot 7 \\
41 \cdot 9 \\
92 \cdot 1\end{array}$ & $\begin{array}{c}5.4 \text { to } 27.5 \\
3.4 \text { to } 44.1 \\
4.2 \text { to } 93.0 \\
9.4 \text { to } 45.6 \\
22.7 \text { to } 77.2 \\
60.3 \text { to } 140.8\end{array}$ \\
\hline $60-69$ & $\begin{array}{l}\text { Chinese } \\
\text { Filipino } \\
\text { Japanese } \\
\text { Hispanic } \\
\text { Black } \\
\text { White }\end{array}$ & $\begin{array}{r}13 \cdot 0 \\
15 \cdot 6 \\
21 \cdot 2 \\
45 \cdot 5 \\
85 \cdot 0 \\
128 \cdot 7\end{array}$ & $\begin{array}{c}4.3 \text { to } 38.9 \\
2.9 \text { to } 83.0 \\
1.6 \text { to } 288.5 \\
20.0 \text { to } 103.5 \\
46.7 \text { to } 154.8 \\
91.1 \text { to } 181.8\end{array}$ & $\begin{array}{r}27 \cdot 2 \\
27 \cdot 4 \\
44 \cdot 0 \\
46 \cdot 1 \\
93 \cdot 2 \\
205 \cdot 0\end{array}$ & $\begin{array}{c}12.8 \text { to } 57.4 \\
7.9 \text { to } 94.8 \\
9.7 \text { to } 199 \cdot 4 \\
22.3 \text { to } 95.5 \\
55.4 \text { to } 156.8 \\
157.1 \text { to } 267.5\end{array}$ \\
\hline$>69$ & $\begin{array}{l}\text { Chinese } \\
\text { Filipino } \\
\text { Japanese } \\
\text { Hispanic } \\
\text { Black } \\
\text { White }\end{array}$ & $\begin{array}{r}22 \cdot 4 \\
26 \cdot 9 \\
36 \cdot 6 \\
78 \cdot 5 \\
146 \cdot 6 \\
221 \cdot 8\end{array}$ & $\begin{array}{r}7.6 \text { to } 66 \cdot 1 \\
5 \cdot 1 \text { to } 140 \cdot 7 \\
2.7 \text { to } 494 \cdot 6 \\
35 \cdot 2 \text { to } 174.9 \\
82.9 \text { to } 259 \cdot 2 \\
170.8 \text { to } 288 \cdot 1\end{array}$ & $\begin{array}{r}40 \cdot 1 \\
40 \cdot 4 \\
65 \cdot 0 \\
68 \cdot 1 \\
137 \cdot 5 \\
302 \cdot 2\end{array}$ & $\begin{array}{r}19.2 \text { to } 83.6 \\
11.7 \text { to } 139.1 \\
14.3 \text { to } 293.6 \\
33.5 \text { to } 138.3 \\
83.5 \text { to } 226.3 \\
257.7 \text { to } 358.5\end{array}$ \\
\hline
\end{tabular}

$\mathrm{CL}=$ Confidence limits (lower and upper).

was least pronounced among the Chinese and Hispanic patients (table 4).

Using logistic regression for each sex, statistically significant effects were found for both race and age. No interaction effect between race and age was found to be statistically significant for either sex. Using the estimated probabilities of a patient undergoing a total hip replacement for primary coxarthrosis obtained from this model, we calculated both the estimated rate of the primary osteoarthritic hip per 100000 population per year and its associated two sided $90 \%$ confidence interval (table 5). Statistical differences became more profound in the older age groups, which is to be expected for a late onset disease such as primary coxarthrosis.

Except for avascular necrosis, the incidence of individual diagnoses requiring THR was too small for meaningful comparison (table 4). Avascular necrosis had a strikingly increased incidence in the black population compared with white subjects (5.7 $v 4.6$ per 100000 population for women and $9.3 v 1.5$ for men).

\section{Discussion}

This study documented the rates of total hip arthroplasty in a large urban centre for the Asian, black, Hispanic, and white populations over a five year period. The THR rate of 75 per 100000 white San Franciscans is comparable to that reported for the United States as a whole and somewhat below the national rates in Sweden, Denmark, and Norway. Rates for all total hip arthroplasty in the white population in this study were 10 times those for Asian and two to six times those for black and Hispanic San Franciscans.

The data on racial rates of total hip arthroplasty for complaints of various aetiologies clearly document the huge increases in rates of total hip arthroplasty for osteoarthritis in the white compared with the non-white population. The white subjects had an incidence of total hip arthroplasty for primary coxarthrosis two and a half to three times the rate for black subjects and 15-20 times the rate for Asians.

Whether the actual interracial differences of hip disease are this large is a question for further investigation. This study focused on surgical patients; access to surgical care, sociocultural factors influencing the decision for surgery, and even different indications for surgery by different surgeons could affect the numbers coming to surgery. Nevertheless, observations based on these data would suggest that such factors do not account significantly for the wide differences in THR rates that we found between racial groups. First, Asian, black, and Hispanic subjects who sought total hip replacement surgery did so in disproportionate numbers for diseases other than primary coxarthrosis. Of the Asian group, only $18-28 \%$ of those receiving a total hip had primary coxarthrosis; for the black and Hispanic groups the rate was $52-54 \%$, compared with $66 \%$ for the white group. If the non-white populations sought and received the treatment for the other causes of a painful hip, it can be argued that they would also seek treatment for a painful osteoarthritic hip. Second, other incidence studies have found that the THR rate for avascular necrosis in the black population ${ }^{16}$ is much greater than for white subjects. One can speculate that if, for patients undergoing total hip replacement for avascular necrosis, there is a significant black/ white rate differential, then the rate of 
coxarthrosis in patients getting THR (which for the black population was $33 \%$ that for white subjects) would likewise be representative of the population for THR.

We recognise that this study does not address questions of medical access and possible sociocultural factors. These factors aside, we believe that our methodology does not account for the significant rate differences observed. We did not specifically verify the racial classification of each patient, but believe it to have been reasonably accurate. Random review of the medical records, in cases where the treating doctor had classified the patients as black or Asian, showed no discordance between the doctor's classification and the hospital's computer printout. We found three female cases identified by computer printout racial code as Asian, but with a married name typical of the white population. We did not have a means to judge mixed parentage. Radiographic validation was performed without knowledge of the patient's age or race, except in those cases where Chinese or Japanese surnames appeared on the radiographs. Since San Francisco hospitals provided twice as many THRs to patients from outside San Francisco as to city residents, San Francisco can be considered a referral center for this operation. Therefore it is unlikely that a significant number of San Francisco residents sought total hip replacement elsewhere.

\section{Conclusion}

The distribution of primary coxarthrosis in patients undergoing total hip replacement in this study parallels rates reported internationally. ${ }^{1} 27$ 10-12 The low rates among Asians, in San Francisco as in Asian countries, is particularly striking. Although population based rates of primary coxarthrosis are extremely low for black Jamaicans and black South Africans, the rates in black San Franciscans appear to be relatively higher than in those countries.

The results of the current study may be useful in interpreting variations in rates of total hip arthroplasty in different geographic regions. Based on our findings, for example, states with large black and Asian populations ${ }^{17}$ would be expected to have lower rates of all total hip replacement. The findings in this study, based on surgical patients, suggest that random population surveys of different races living in the same locale would probably reveal great variation in the rate of primary coxarthrosis and could lead to an understanding of its aetiology.

The authors wish to thank Richard Juster, PhD for help with the statistical analysis of the data.

1 Hoaglund F T, Shiba R, Newberg A H, Leung K Y K. Diseases of the hip: A comparative study of Japanese Diseases of the hip: A comparative study of Japanese Am 1985; 67: 1376-83.

2 Lawrence JS, Sebo M. The geography of osteoarthritis. In: Nuki G, ed. The etiopathogenesis of osteoarthrosis. Baltimore: University Park Press, 1980; 155-83.

3 Van Saase J L C M, Van Romunde L K J, Cats A Vandenbroucke J P, Valkenburg H A. Epidemiology of osteoarthritis: Zoetermeer survey. Comparison of radiological osteoarthritis in a Dutch population with that in 10 other populations. Ann Rheum Dis 1989; 48: 271-80.

4 Danielsson L G. Incidence and prognosis of coxarthrosis. Acta Orthop Scand 1964; (suppl) 66: 1-114.

5 Goldie I. Total hip and knee replacements. Acta Ortho Scand 1991; 62 (suppl 241): 23-6.

6 Malchau H, Herberts P, Ahnfelt L. Prognosis of total hip replacements in Sweden: Followup of 92,675 operations performed 1978-1990. Acta Orthop Scand 1993; 64: performe

7 Hoaglund F T, Yau A C M, Wong W L. Osteoarthritis of the hip and other joints in Southern Chinese in Hong Kong. F Bone foint Surg Am 1973; 55: 545-57.

8 Mukhopadhaya B, Barooah B. Osteoarthritis of the hip in Indians: An anatomical and clinical study. Indian $\mathcal{F}$ Orthop 1967; 1: 55-62.

$9 \mathrm{Kim} \mathrm{Y} \mathrm{H,} \mathrm{Suh} \mathrm{J} \mathrm{S.} \mathrm{Low} \mathrm{incidence} \mathrm{of} \mathrm{deep} \mathrm{venous}$ thrombosis after total hip replacement. F Bone foint Surg Am 1988; 70: 878-82.

10 Nakamura $S$, Ninomiya $S$, Nakamura $T$. Primary osteoarthritis of the hip in Japan. Clin Orthop 1989; 241. osteoa $190-6$.

11 Solomon L, Beighton P, Lawrence J S. Rheumatic disorders in the South African Negro. II. Osteoarthritis. South Af Med f 1975; 49: 1737-40

12 Bremner J M, Lawrence J S, Miall W E. Degenerative joint disease in a Jamaican rural population. Ann Rheum Dis 1968; 27: 326-32.

13 Stulberg S D, Harris W H. Acetabular dysplasia and development of osteoarthritis of the hip. Proceedings of the Second Open Scientific Meeting of the Hip Society. St Louis: CV Mosby, 1974; 82-92.

14 United States Department of Commerce Census Table PB5, 1990 Census, Summary Tape File 2, 915 L Street, Sacramento, CA 95814

15 Anderson S, Auquier A, Hauck W W, Oakes D, Vandaele W, Weisberg H I. Statistical methods for computative studies. New York: John Wiley, 1980; $113-38$.

16 Lennox D W, Xixic T M, Ebert T. The relative importance of various risk factors in determining site and number of bones involved with osteonecrosis. In: Arlet J, Maziere $\mathrm{B}$, eds. Bone circulation and bone necrosis. Proceedings of the 4th International Symposium on Bone Circulation New York: Springer Verlag, 1987; 328-30.

17 Peterson M, Hollenberg J P, Szatrowski T P, Johanson N A, Mancuso C A, Charlson M E. Geographic variation in the rates of elective total hip and knee arthroplastie among MediCare beneficiaries in the United States. $f$ Bone foint Surg Am 1992; 4: 1530-9. 